tive examination. Internal morphology of the left appendage revealed a smooth endocardium without a crista terminalis and was of the left atrial type. The presence of left atrial isomerism associated with a common atrium led to the diagnosis of ambiguous AV connection. Surgical correction involved rerouting the systemic venous return to the tricuspid valve. This was achieved with a "mirror image" Mustard operation. The Senning operation was not indicated because of a lack of tissue in the atrial septum.

Localization of the conductive tissue is difficult. Two AV nodes may be present. ${ }^{4} \mathrm{~A}$ similar pattern is found in AV and ventricular discordance (corrected transposition). The posterior node is hypoplastic, and the His bundle originates from the anterior node. Anderson et $\mathrm{al}^{5}$ showed that the posterior node could be connected with the His bundle. In situs inversus the posterior node is predominant, but not always so. A sling of conductive tissue could be found with fibers around the anterior and posterior margins of the ventricular septal defect.
Uncertainty of the correct location of the conducting tissue explains the high frequency of complete AV dissociation following surgical repair when an AV septal defect is present. ${ }^{6}$ Suturing the interatrial baffle into place with a beating heart could help to avoid damage to the His bundlc; however, in small patients, as was ours, this can be difficult to achieve.

1. Macartney FJ, Zuberbuhler JR, Anderson RH. Morphological considerations pertaining to recognition of atrial isomerism. Consequences for sequential chamber localization. Br Heart I 1980;44:657-667.

2. Pillai R, Lima R, Anderson R, Shinebourne E, Lincoln C. Surgical correction in mirror-image atrial arrangement or left atrial isomerism with systemic venous return to the left sided atrium. I Thorac Cardiovasc Surg 1983;86:288293.

3. Shinebourne EA, Macarteney FJ, Anderson RH. Sequential chamber localization: logical approach to diagnosis in congenital heart disease. Br Heart J 1976;38:327-332.

4. Dickinson DF, Wilkinson JL, Anderson KR, Smith A, Ho SY, Anderson RH. The cardiac conduction system in situs ambigus. Circulation 1979;59:879 885

5. Anderson RH, Becker AE, Arnold R, Wilkinson JL. The conducting tissues in congenitally corrected transposition. Circulation 1974;50:911-923.

6. Baudet EM, Hafez A, Choussat A, Roques X. Isolated ventricular inversion with situs solitus. Successful surgical repair. Ann Thorac Surg 1986:41:91-94.

\section{Aortic Aneurysms After Subclavian Angioplasty Repair of Coarctation of the Aorta}

\author{
MONICA M. MARTIN, MD \\ ROBERT H. BEEKMAN, MD \\ ALBERT P. ROCCHINI, MD \\ DENNIS C. CROWLEY, MD \\ AMNON ROSENTHAL, MD
}

thas been over 10 years since aortic aneurysms after synthetic patch repair of coarctation of the aorta were first reported. More recent studies suggest that late aneurysm formation after synthetic patch angioplasty may occur in up to $38 \%$ of patients. ${ }^{1,2}$ These aneurysms typically occur in the aortic wall opposite the synthetic patch, perhaps resulting from stress exerted on abnormal tissue in that portion of the aorta. As is the case with synthetic patch repair, the aortic wall of the coarctation and periductal area is not excised in the subclavian angioplasty procedure. Late aneurysm formation might therefore be expected to occur after subclavian angioplasty as well. In this report we describe 3 children who developed aortic aneurysms following left subclavian angioplasty repair of coarctation.

Case 1: An infant presented during the second week of life with Turner syndrome, congestive heart failure, a discrete thoracic coarctation and severe valvar aortic stenosis. At 12 days of age the coarctation was repaired using the left subclavian angioplasty procedure. An intraluminal web at the site of the coarcta-

From the Division of Pediatric Cardiology, Department of Pediatrics, C.S. Mott Children's Hospital, University of Michigan, Ann Arbor, Michigan. Manuscript received October 1, 1987; revised manuscript received November 16, 1987, and accepted November 22 tion was excised and the subclavian flap was sutured with running 7-0 prolene. At the end of the procedure the patient was normotensive and had no residual coarctation gradient. A surgical aortic valvotomy was performed at 2 months of age. At age 4.5 years a chest $\mathbf{x}$-ray revealed a prominence of the aorta in the area of the coarctation repair (Figure 1). Although an echocardiogram disclosed no abnormality of the aortic

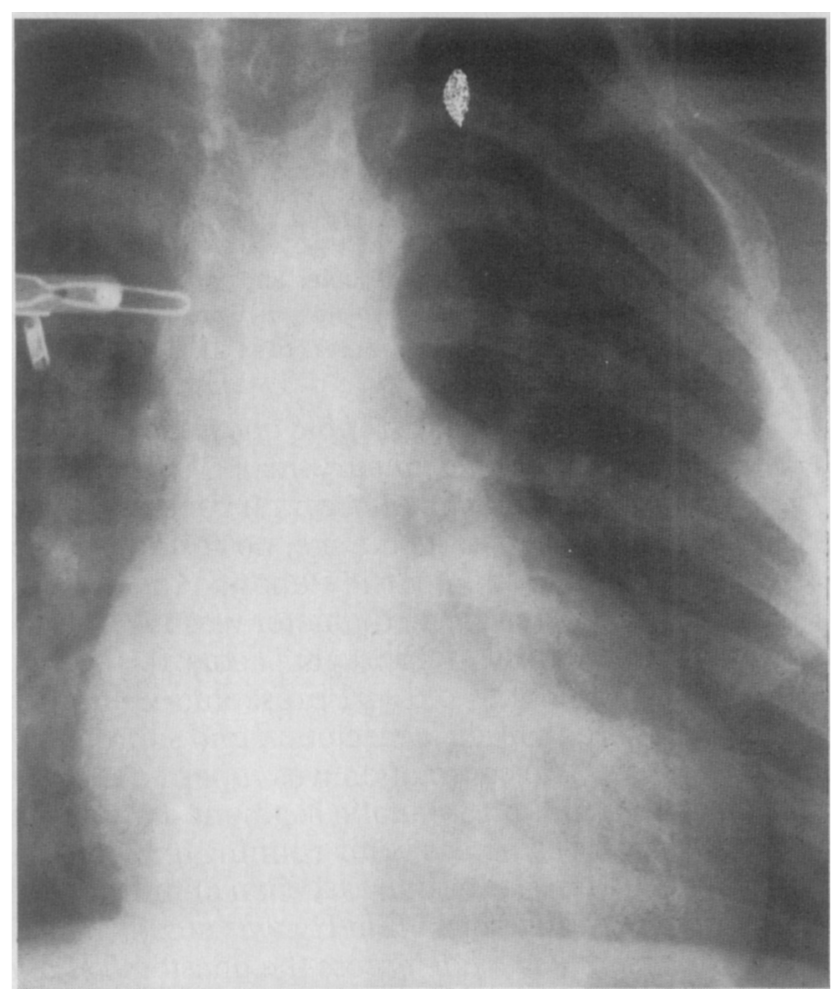

FIQURE 1. Posteroanterior chest $x$-ray showing a prominent dilatation in the area of prior coarctation repair in a 4.5-year-old asymptomatic girl who had a left subclavian angioplasty procedure at $\mathbf{1 2}$ days of age (case 1). 
TABLE I Findings After Subclavian Angloplasty Repair of Coarctation of the Aorta

\begin{tabular}{ccclcc}
\hline Pt & Age & $\begin{array}{c}\text { Ratio of } \\
\text { Repair to } \\
\text { (yrs) }\end{array}$ & DS Aorta & Aneurysm & \multicolumn{2}{c}{ Identlfied by } \\
Extension & CXR & Echo \\
\hline 1 & 4.5 & 1.5 & P,L,M & + & 0 \\
2 & 3 & 1.6 & P,L & 0 & 0 \\
3 & 2 & 2.8 & A,L.M & + & + \\
\hline
\end{tabular}

$A=$ anterior $C X R=$ chest $\mathrm{X}$-ray; $\mathrm{DS}=$ descending; $\mathrm{L}=$ lateral; $M=$ medial; $P=$ posterior

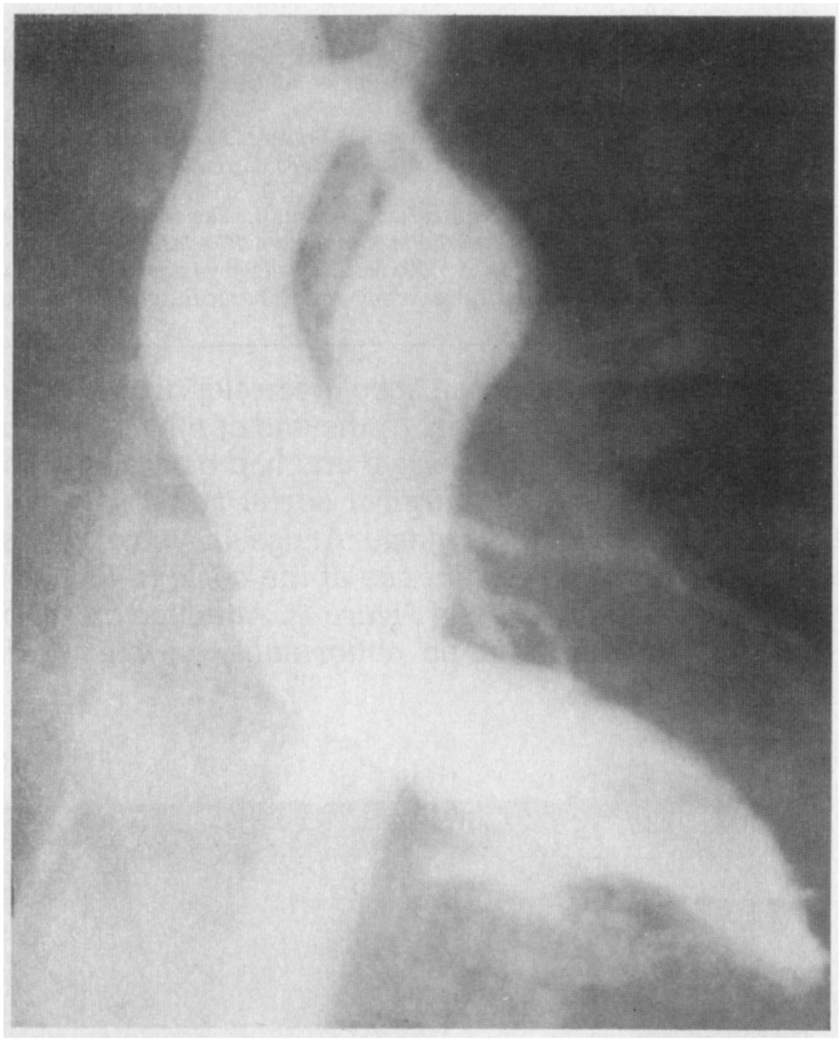

FIGURE 2. Anteroposterlor left ventricular anglogram demonsirating an aortic aneurysm in a 3-year-old girl who underwent left subclavian angloplasty 21 months earller (case 2 ).

arch, a computerized tomographic chest scan suggested the presence of a small aneurysm of the coarctation repair site. A cardiac catheterization revealed aneurysmal dilatation of the repair site, no residual coarctation gradient und mild aortic stenosis. Angiography revealed that the aneurysm diameter was $150 \%$ of the aortic diameter at the diaphragm (Table I).

Case 2: A 15-month-old girl presented with heart failure, a severe thoracic coarctation and supravalvar mitral stenosis. The coarctation was repaired with resection of a 3-mm long stenotic segment and end-toend anastomosis using posterior running and anterior interrupted 7-0 prolene sutures. When an intraoperative residual gradient of $35 \mathrm{~mm} \mathrm{Hg}$ was noted, a longitudinal incision was made across the anastomosis and a left subclavian angioplasty was performed using running 7-0 prolene sutures. The coarctation gradient was reduced to $5 \mathrm{~mm} \mathrm{Hg}$ and the patient was normotensive after the operation. A cardiac catheterization at age 3 years revealed an aneurysmal dilatation at the repair site and no residual coarctation gradient. The diameter of the aneurysm by angiography was $160 \%$ of the diameter of the aorta at the diaphragm (Figure 2). The aneurysm had not been detected by echocardiogram or chest $\mathrm{x}$-ray.

Case 3: A boy with Taussig-Bing anomaly and discrete thoracic coarctation presented in early infancy with congestive heart failure and cyanosis. At 6 weeks
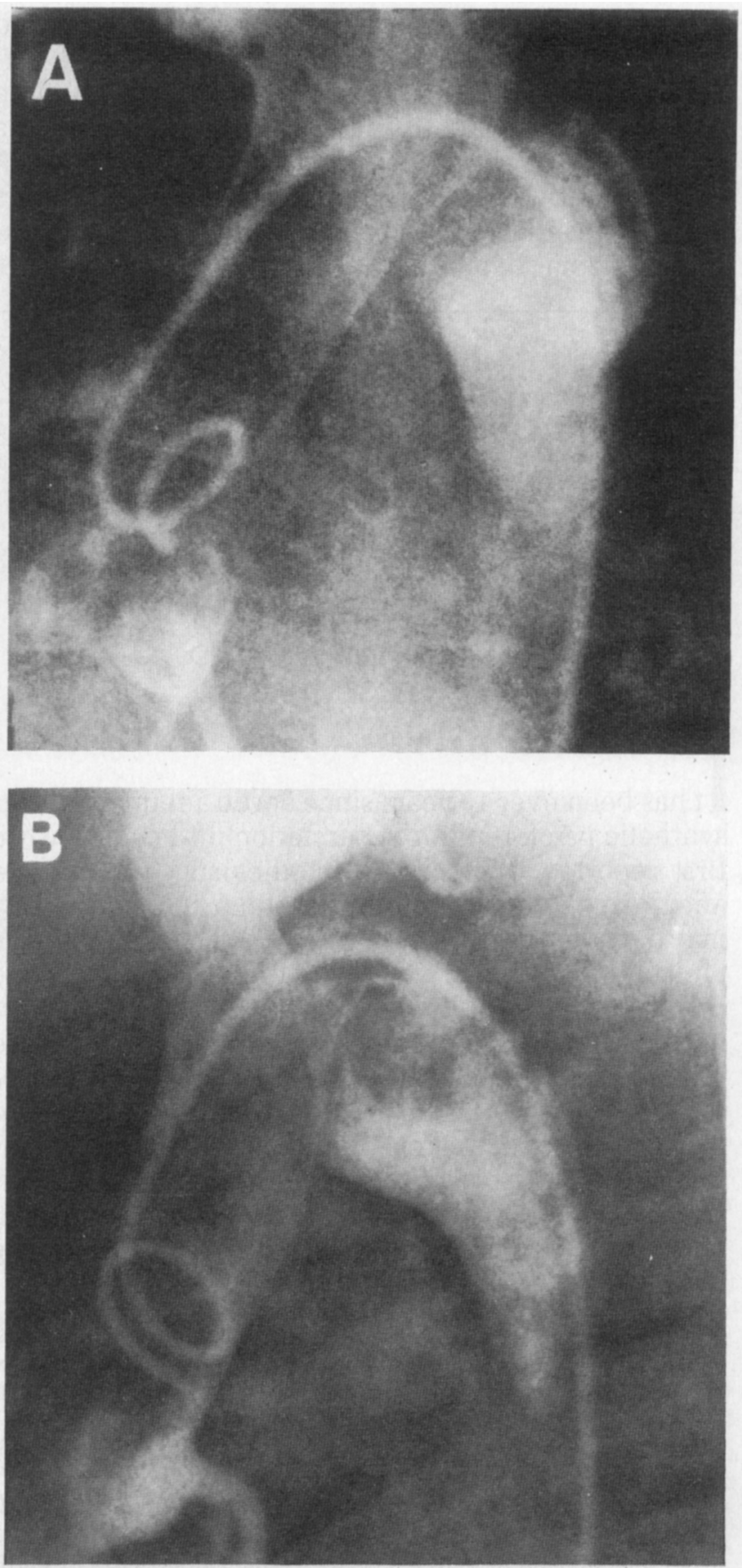

FIGURE 3. Ten ${ }^{\circ}$ left anterior oblique $(A)$ and lateral $(B)$ aorlograms confirming the presence of a large circumferentlal aneurysm in a 2year-old boy who had left subclavlan repair of a coarctation at age 6 weeks (case 3). 
of age he underwent a left subclavian angioplasty repair of the coarctation and pulmonary artery banding. The subclavian flap was sutured with 7-0 prolene. After the operation there was no residual coarstation gradient and the patient was normotensive. At age 2 years an echocardiogram suggested the presence of an aortic aneurysm and a cardiac catheterization was performed. Angiography revealed aneurysmal dilatation at the coarctation repair site, the diameter of which was $280 \%$ of the aortic diameter at the diaphragm (Figure 3). No residual coarctation gradient was present.

Subclavian angioplasty, introduced in 1966 by Waldhausen and Nahrwold, ${ }^{3}$ has been recommended by some as the surgical procedure of choice for repair of coarctation of the aorta in infancy. Because the procedure avoids a circumferential suture line and uses viable tissue as a patch, it has been hoped that it would avoid the late problems documented after other types of repair, namely restenosis (after resection and endto-end anastomosis) and aneurysm formation (after synthetic patch aortoplasty). As long-term follow-up data are acquired, however, the early enthusiasm for the subclavian angioplasty repair may prove to be unwarranted. Recent data suggest that recurrent coarctation may develop more often after subclavian angioplasty than previously suspected. ${ }^{4}$ And now, we report instances of aortic aneurysms occurring at the site of a subclavian angioplasty repair.

The synthetic patch aortoplasty technique for coarctation repair was first described by Vosschulte in $1957 .{ }^{5}$ As is now the case with subclavian angioplasty, aneurysms occurring at the repair site were not described until nearly 20 years later. In 1976 , aortic aneurysms were described in 5 patients from Vosschulte's original series. ${ }^{6}$ Late aneurysm formation has since been reported to be as high as $38 \%$ after a synthetic patch repair of coarctation.1,2 Although most of the previous reports have not explicitly defined whal constitutes an aneurysm in the absence of pathologic material, fusiform dilatation of the repair site with a diameter $\geq 150 \%$ of the patient's descending aorta correlates well with the presence of an aneurysm. ${ }^{2}$ This criterion (comparing the diameter of the dilated vessel to that of the adjacent uninvolved vessel) has also been used to define aneurysms of other muscular arteries as, for example, coronary arteries in Kawasaki disease, and has been applied in the present report.
The mechanism of aneurysmal aortic dilatation after synthetic patch repair of a coarctation may relate to increased tension transmitted by the patch to the more elastic abnormal aortic wall opposite the repair. It was suggested by Moulton in 1983 that late aneurysm formation may be expected regardless of whether the patch is a synthetic material or subclavian artery tissue, since abnormal tissue of the coarctation and periductal area is not excised in either repair. ${ }^{8}$ The first aneurysms after subclavian angioplasty have now been documented, lending support to Moulton's concept. It is of interest that in case 2 an aneurysm developed despite coarctation resection before subclavian angioplasty; it may be that a suture line is as vulnerable to excessive wall stress opposite a patch as is native aortic tissue.

Because no patient in this series underwent aneurysm resection, we do not have pathologic data regarding the nature and location of the lesions. We intend to follow these children closely and recommend resection if evidence of progressive aneurysmal dilatation is found. Nevertheless, the clinical data presented indicate that children who have undergone subclavian angioplasty, much the same as those who have had a synthetic patch repair, warrant long-term serial evaluation for possible development of an aneurysm at the coarctation repair site. Long-term studies are necessary to accurately define the incidence and natural history of late aneurysm formation after the subclavian angioplasty procedure.

1. Clarkson PM, Brandt PW, Barratt-Boyes BG, Rutherford ID, Kerr AR, Neutze IM. Prosthetic repair of coarctation of the aorta with particular reference to Dacron onlay patch grafts and late aneurysm formation. $\Lambda \mathrm{m}$ J Cardiol 1985;56:342-346

2. Bromberg BI, Beekman RH, Bank ER, Snider AR, Rocchini AP. Aneurysms following prosthetic patch repair of coarctation: an evaluation of prevalence and screening techniques (abstr). Circulation 1986;74(II):467.

3. Waldhausen IA, Nahrwold DL. Repair of coarctation of the aorta with a subclavinn flap. I Thorac Cardiovasc Surg 1966;51:532-533.

4. Beekman RH, Rocchini AR, Behrendt DM, Bove EL, Dick M, Crowley DC, Snider AR, Rosenthal A. Long-term outcome after repair of coarctation in infancy: subclavian angioplasty does not reduce the need for reoperation. IACC 1986;8:1406-1411.

5. Vosschulte K. Isthmusplastik zur behandlund der aortem isthmusstenose. Thoraxchir 1957;4:443-450.

6. Walter P, Flamung W, Hehrlein FW. Fruh und spatkomplikationen nach direkter und indirekter aortenisthmusplastik. Thoraxchir 1976;24:369-372. 7. Furusho K, Nakano H, Shinomiya K, Tamura T, Manabe Y, Kawarano M, Baba K, Kamiya T, Kiyosawa N, Hayashidera T, Hirose O, Yokoyama T, Baba $\mathrm{K}$, Mori C. High-dose intravenous gammaglobulin for Kawasaki disease. Lancet 1984;2:1055-1058.

8. Moulton AL, Brenner JI, Roberts G, Tavares S, Ali S, Nordenberg A, Burns JE, Ringel R, Berman MA, McLaughlin JS. Subclavian flap repair of coarctation of the aorta in neonates: realization of growth potential? J Thorac Cardiovasc Surg 1984;87:220-235. 